\title{
SUSTENTABILIDADE AMBIENTAL: PARÂMETRO NECESSÁRIO A ATIVIDADE ECONÔMICA E REQUISITO ESSENCIAL A CONCESSÃO DE BENEFÍCIOS FISCAIS
}

\author{
Ana Alice De Carli ${ }^{1}$ \\ Leonardo De Andrade Costa ${ }^{2}$
}

\begin{abstract}
Resumo
O presente texto tem por desiderato demonstrar a importância da correlação entre o princípio da sustentabilidade ambiental, a atividade econômica e a concessão de benefícios fiscais, como um caminho a percorrer para o equilíbrio do Meio Ambiente natural e como instrumento de educação ambiental, considerando imperiosa necessidade de mudanças de paradigmas, em que a ética do cuidado deve ser elevada ao patamar de premissa fundamental, porquanto a natureza não pode mais ser tratada como mero objeto ao dispor do homem, Com efeito, a análise parte da junção de múltiplas nuances desustentabilidade.
\end{abstract}

Palavras-Chave: sustentabilidade ambiental; atividade econômica; tributação; direito.

\section{INTRODUÇÃO}

As questões ambientais têm sido o mote de muitos encontros de especialistas, governantes e de outros atores sociais ao redor do mundo, em especial daqueles responsáveis pela gestão empresarial de um lado e pela formulação e operacionalização de políticas públicas deoutro.

O presente texto objetiva demonstrar a importância da sustentabilidade ambiental como princípio norteador da atividade econômica e, bem assim, da política tributária, que afeta diretamente os custos empresariais. Ou seja: busca-se revelar a complexa e intrincada correlação entre a proteção ambiental, a atividade econômica e o papel extrafiscal das diferentes espécies tributárias, que podem servir de instrumentos eficientes para indução de novos comportamentos, além da sua função redistributiva de renda e riqueza.

\footnotetext{
${ }^{1}$ Doutora e Mestre em Direito Público e Evolução Social. Professora Ajunta do Curso de Direito e do Mestrado em Tecnologia Ambiental. E-mail:ana.nado@globo.com

${ }^{2}$ Coordenador da Pós-Graduação Lato Sensu em Direito Tributário da FGV Direito Rio. Professor da Graduação e da PósGraduação da Fundação Getúlio Vargas do Estado do Rio de Janeiro (FGV Direito Rio). Mestre em Direito Econômico e Financeiro por Harvard Law School, Cambridge, MA. International TaxProgram/ Universidade de São Paulo (USP). Pósgraduado lato sensu em contabilidade pela Escola de Pós-Graduação em Economia da Fundação Getulio Vargas (EPGE/FGV). Bacharel em Economia e Direito pela Pontifícia Universidade Católica do Rio de Janeiro (PUC-RJ).E-mail: leonardo.costa@fgv.br
} 
A complexidade do tema decorre de sua natureza multidimensional, com causas e efeitos recíprocos indissociáveis, que incorporam elementos das ciências naturais, das ciências humanas e sociais aplicadas, assim como da tecnologia, todos em permanente tensão e conexão no tempo. Nesse sentido, deve-se enfatizar a inevitável e mútua vinculação entre as ações privadas individuais e do mercado empresarial em face das ações do governo e das políticas públicas, onde se inserem, entre outras, aquelas de caráter regulatório ambiental e tributário.

Nesse cenário é importante salientar a evolução e a insuficiência do pensamento cientificista linear fragmentário para compreensão dos fenômenos pluridimensionais e interdisciplinares, cujo estudo pressupõe uma abordagem sistêmica (LUHMANN, 1983), essencial para maior aproximação e melhor compreensão da realidade dinâmica, multifacetada e indissociavelmenteinterconectada.

Com efeito, não é novidade para ninguém que o pensamento contemporâneo não comporta mais as ideias propagadas especialmente a partir da denominada Revolução Científica, ocorrida entre os Séculos XVI e XVII, a qual enfatizou uma visão ontológica e epistemológica de mundo, em que a natureza era vista como mero objeto a serviço das necessidades e desejos do homem.

Nessa vertente de raciocínio destacam-se Francis Bacon, Galileu e René Descartes. Francis Bacon (assim como Galileu e Descartes) defendia que a Natureza deveria ser dominada pela racionalidade humana. Segundo Galileu, o conhecimento matemático era o instrumento mais confiável para compreendê-la e controlá-la. Descartes, por sua vez, apregoava a separação da matéria (que denominava de res extensa) da mente (a res cogitans), o que, na verdade, visava negar a existência da anima mundi, sob o argumento de que "a única entidade não-mecânica do universo, o único lugar de subjetividade e alma, era a própria psique humana" (HARDING, 2008).

O inegável avanço tecnológico, decorrente da designada Revolução Científica, e bem assim os incomensuráveis ganhos proporcionados para a qualidade de vida de um número substancial de pessoas, especialmente sob o ponto de vista material, não afastam a necessidade de reconhecimento que a lei da entropia (GEORGESCU ROEGEN, 2012) molda a natureza, a qual, além de conformar a razão humana também impõe limites e restrições ao modelo econômico (CECHIN, 2010) de produção e consumo de bens eserviços.

$\mathrm{Na}$ atualidade, deve-se reconhecer que a preservação e a proteção dos bens ambientais, que encontram na sustentabilidade sua base principiológica, dependem de múltiplos setores de produção e de serviços, inclusive financeiros (COSTA, 2015) o que demanda vasto e intrincado aparato normativo, responsável por disciplinar tais mercados e endereçar as principais ameaças apontadas pela comunidade global (dentre outras, ressaltam-se as mudanças climáticas, o desmatamento, a poluição, a perda de biodiversidade e o aumento vertiginoso da população, a qual traz a reboque demandas variadas de consumo). 
A Carta Magna brasileira de 1988, em seu art. 225, estabelece normas de caráter didático e regulatório, além de apresentar a natureza jurídica do meio ambiente, como um "bem de uso comum do povo", ou seja, na classificação doutrinária de direitos fundamentais, seria um direito difuso, implicando amplo e indefinido patamar de titulares - não se restringindo apenas aos indivíduos, mas também aos demais seres vivos da fauna e da flora (CARLI, 2015.a). Neste dispositivo é possível extrair o princípio da sustentabilidade ambiental, especialmente nos incisos IV e $\mathrm{V}$ do $\$ 1^{\circ}$, os quais estabelecem como prerrogativas do PoderPúblico:

Exigir, na forma da lei, para instalação de obra ou atividade potencialmente causadora de significativa degradação do meio ambiente, estudo prévio de impacto ambiental, a que se dará publicidade; e controlar a produção, a comercialização e o emprego de técnicas, métodos e substâncias que comportem risco para a vida, a qualidade de vida e o meio ambiente.

Apesar de o conteúdo da normativa constitucional acima transcrita definir como competência do Poder Público a disciplina e o controle da realização de atividades econômicas, isso não afasta o dever de cada cidadão de denunciar indícios ou evidências de irregularidades comprometem o habitat natural, cujo fundamento encontrase no caput do art. 225, o qual merece destaque:

Todos têm direito ao meio ambiente ecologicamente equilibrado, bem de uso comum do povo e essencial à sadia qualidade de vida, impondo-se ao Poder Público e à coletividade o dever de defendê-lo e preservá- lo para as presentes e futurasgerações.

A Constituição Federal de 1988 traz alguns instrumentos de cidadania, com as quais as pessoas podem agir em defesa do meio ambiente. No art. 50, inciso LXXIII, por exemplo, há previsão da Ação Popular, que o cidadão poderá manejála sem pagamento de custas, além do direito de representação junto ao Ministério Público, nos termos do art. $74, \$ 2^{\circ}$, também da Carta em comento.

Ainda no âmbito constitucional, oportuno destacar que no capítulo que trata da Ordem Econômica o constituinte derivado plasmou no art. 170 os princípios norteadores da atividade econômica, entre os quais consta a defesa do Meio Ambiente. A rigor, tal princípio foi inserido pela Emenda à Constituição no 42/2003. A melhor exegese que se pode construir desta previsão (tardia) constitucional é a de que toda atividade antrópica de natureza econômica deve ter como premissa inafastável a observância e concretização do princípio da sustentabilidade ambiental, merecendo tratamento diferenciado conforme o impacto ambiental em todas as fases das atividades, ou seja, as externalidades negativas ambientais precisam ser avaliadas desde o projeto de elaboração do produto ou do serviço até seu descarte ou etapa final, internalizando, de alguma forma, os custos decorrentes de prejuízos (CARLI,2015).

Nesse contexto, reconhece-se que a complexidade do tratamento jurídico dispensado às muitas questões ambientais envolve uma intrincada rede de normas. $\mathrm{O}$ aparelho regulatório e as políticas adotadas são bastante vastos, o que impõe um desafio para as autoridades responsáveis por controlar e disciplinar as diversas atividades econômicas e bem assim àqueles responsáveis pela gestão da atividade econômicaprivada.

Desse modo, busca-se com a presente reflexão trazer à luz alguns aspectos que aproximam questões e vol.09, nº. 02, Rio de Janeiro, 2016.pp. 843-860 
matérias aparentemente distintas ou desconexas se adotada uma concepção clássica do Direito, mas cuja harmonia e vinculação se impõem na atualidade, isto é, o meio ambiente, a empresa e atributação.

O estudo das diversas dimensões em que se interligam a questão ambiental, a atividade empresarial e os tributos pressupõe a compreensão do âmbito de eficácia da sustentabilidade multidimensional, em especial que a adoção desse parâmetro de forma abrangente altera o processo decisório privado e público, no plano político, gerencial, administrativo e judicial, com efeitos substanciais sobre o Direito em suas diversas projeções: como o Direito Empresarial, o Direito Econômico, o Direito Financeiro e o Direito Tributário, sem descuidar do próprio Direito Ambiental.

Assim, no próximo capítulo, que versa sobre as múltiplas faces da sustentabilidade, tem-se por desiderato apresentar aspectos conceituais relevantes para o que se propõe neste trabalho. Em seguida, no capítulo 3, buscase apresentar a sustentabilidade ambiental no contexto da atividade econômica em sentido lato, a qual, conforme lições de Eros Roberto Grau (GRAU, 2003), é um gênero que comporta algumas espécies, a atividade econômica stricto sensu e os serviços públicos. Assim, nos arts. 170 e 174 da Carta Constitucional de 1988 encontra-se a atividade econômica em sentido lato, enquanto no art.173 tem-se o perfil da atividade econômica em sentido estrito, que pode ser explorada pelo Estado, desde que haja relevante interesse coletivo, ou quando se tornar imperiosa para a segurança do país. Já o art. 175, também do diploma constitucional em tela, tem-se o serviço público.

Por sua vez, antes das considerações finais, no capítulo 4, serão abordadas as múltiplas conexões entre a tributação e o meio ambiente, matéria que se projeta sobre a atividade econômica privada, em especial como os tributos afetam os custos empresarias e o retorno do capital privado.

\section{A SUSTENTABILIDADE EM SUAS MÚLTIPLAS DIMENSÕES}

O vocábulo sustentabilidade - que possui múltiplas dimensões semânticas - tem sido muito utilizado na atualidade. Segundo Fábio Nusdeo (MARQUES, 2009), a expressão sustentabilidade surgiu no campo das Ciências Econômicas, com o objetivo de diferenciar crescimento econômico de desenvolvimento econômico. O autor em tela estabelece distinção importante entre desenvolvimento e crescimento econômicos: enquanto o desenvolvimento econômico pode "apresentar condições de se autossustentar", por arregimentar durante seu processo mecanismos de sustentação, o crescimento, "por lhe faltarem tais condições, acaba por se resolver numa mera sucessão de ciclos, sem que se altere a estrutura básica de economia, a qual entre um ciclo e outro volta a chafurdar-se na estagnação e, mesmo, retrocesso", explica o pesquisador.

John Elkington, em 1994, ao tentar delinear a sustentabilidade no universo corporativo, propôs que seu conteúdo estaria calcado em três pilares, the triple bottom line (TBL), não se limitando apenas ao êxito comercial 
e ao auferimento de lucros das empresas, considerando também aspectos sociais e ambientais. Desse modo, the triple bottom line da sustentabilidade enfeixaria êxito/lucro empresarial + pessoas + meio ambiente (profits, people, planet). Segundo os economistas Timothy F. Slaper e Tanya J. Hall (vide http://www.ibrc.indiana.edu/ibr/2011), "a aplicação do TBL por empresas, governos e organizações sem fins lucrativos são motivados por princípios de sustentabilidade econômica, ambiental e social, mas diferem no que diz respeito à maneira como eles mensuram as três categorias de resultados". A rigor, além dos três elementos propostos por John Elkington, há de se levar em conta também, ao perfilar o conteúdo da sustentabilidade, os aspectos políticos e culturais. Nessa senda, a sustentabilidade estaria firmada em cinco e não em apenas três pilares, os quais seriam: lucro empresarial, pessoas, meio ambiente natural, meio ambiente do trabalho e cultural e aspectos políticos. As relações entre empresa-empregado e empresa-comunidade devem ser construídas a partir da ética do respeito e do cuidado. A seu turno, as políticas públicas (legislativas e administrativas), voltadas para a saudável relação entre meio ambiente natural e meio ambiente do trabalho (relação empresa-empregado e relação empresa-comunidade) também devem ser sustentáveis, a fim de garantir, além de desenvolvimento, a observância dos princípios da dignidade humana, da proteção e preservação ambientais, e do não-retrocesso.

Flavio Ahmed (CARLI e MARTINS, 2013) ao tratar do conceito de meio ambiente, enfatiza a noção de meio ambiente cultural, fazendo menção ao art. 4º do diploma disciplinador da Política Nacional da Educação Ambiental (Lei no 9.795/95) - o qual contempla os princípios que fundamentam tal política-, destacando que tais normas não se limitam ao meio ambiente natural, alçando também o locus cultural. Desse modo, é preciso reconhecer a diversidade cultural "como critério a ser observado (...) como elemento hermenêutico e normativo, em que a própria dimensão natural passa a ser compreendida sob um viés cultural, crítico e humanista", complementa o autor em tela.

Saulo Oliveira P. Coelho e André Fabiano G. Araújo (vide https://mestrado.direito.ufg.br/up/14/o/artigo_prof_saulo.pdf.), a partir de um conceito sistêmico de sustentabilidade, asseveram que "se o desenvolvimento sustentável é um modelo de desenvolvimento, a sustentabilidade pode ser definida como um conceito relacionado à continuidade dos aspectos econômicos, políticos, sociais, culturais e ambientais da sociedade humana”, e, nesses termos, a atividade econômica para se justificar como sustentável deve levar em conta à sua harmonia com o meio ambiente natural e cultural, com o sentido de justiça social, além dos aspectos políticos que permeiam todos esseselementos.

Por sua vez, ensina Juarez Freitas (FREITAS, 2011) que o direito fundamental à sustentabilidade multidimensional irradia efeitos para todas as províncias do Direito, não apenas para o Direito Ambiental, de sorte que o próprio sistema jurídico como que se converte em Direito daSustentabilidade. 
Apesar da complexidade que envolve as questões ambientais e do fato de que toda e qualquer conduta antrópica ou atividade econômica gera certo impacto ao meio ambiente natural, é possível arregimentar mecanismos, por meio dos quais a sustentabilidade ambiental e a atividade empresarial possam buscar o justo equilíbrio.

Assim, por todo o exposto até aqui, constata-se a relevância do princípio da sustentabilidade ambiental como vetor axiológico de todo o sistema jurídico, em especial, da ordem Econômica, do sistema tributário e das políticas de ordenamento urbano.

\section{A SUSTENTABILIDADE AMBIENTAL VIS A VIS A ATIVIDADE ECONÔMICA}

A rigor, além da sustentabilidade ambiental, outros dois institutos, a gestão e a governança, são relevantes para o êxito do processo de preservação e proteção do meio ambiente. Isso porque não basta o discurso, o mais importante é a produção de efeitos no mundo real, o que pressupõe ações concretas, públicas e privadas. Assim, de maneira singela, a gestão compreende ato de gerir ou administrar algo, enquanto a governança, que tem sua origem na ciência política e nas relações internacionais, pressupõe uma forma do exercício do poder "na administração dos recursos sociais e econômicos de um país visando ao desenvolvimento", segundo o documento do Banco Mundial Governance and Development(1992).

A gestão eficiente, sem dúvida, é fator determinante para a proteção, preservação e utilização sustentável dos recursos naturais. Ela tem como pressuposto planejamento adequado, sério e responsável. Em entrevista concedida ao jornalista Tiago Dantas, do jornal O Globo, do dia 8 de novembro de 2014, o engenheiro especializado em recursos hídricos Leo Heller (nomeado para assumir a partir de dezembro de 2014 a relatoria especial da ONU para os direitos à água e ao saneamento básico) afirmou que uma das causas para os problemas de acesso à água com qualidade e quantidade é a falta de planejamento adequado, pontuando o caso recente de escassez de água no maior estado brasileiro em termos populacionais e de atividades econômicas: São Paulo.

O diretor executivo do Programa das Nações Unidas sobre Meio Ambiente (PNUMA), Achim Steiner, no Seminário Internacional - Sistema Financeiro, Economia Verde e Mudanças Climáticas, realizado em São Paulo, no dia 21.09.2015, ressaltou a importância de, a partir do atual cenário de mudanças climáticas, se pensar em uma nova economia, e pontua (CHIARETTI, Jornal VALOR, set.19-21,2015):

Há uma desconexão da economia real, em sua demanda de ter uma agenda de desenvolvimento sustentável, e onde a economia financeira efetivamente está. Temos que criar incentivos para que os mercados invistam em transição. O conceito de "finança verde" é fundamental, assim como o papel dos bancos centrais e das autoridadesregulatórias.

No mesmo evento em São Paulo, Luiz Edson Feltrim, diretor de Relacionamento Institucional e Cidadania do Banco Central pontuou que o sistema financeiro representa "peça-chave na questão ambiental" e complementou: 
É responsável pela intermediação que direciona os recursos para a execução de projetos econômicos. Ao incluir a avaliação socioambiental na análise de riscos dos projetos, o sistema financeiro influencia os preços dos ativos e a própria economia (....). Essa é uma das melhores formas de o sistema financeiro contribuir na conciliação do desenvolvimento socioeconômico com a preservação do meio ambiente.

É de se observar que o Brasil tem procurado, ainda que em passos lentos, atrelar desenvolvimento com sustentabilidade ambiental, e isto se evidencia em algumas políticas legislativas, a começar pela Constituição Federal de 1988, a qual, no capítulo que trata da Ordem Econômica, estabelece tratamento diferenciado para as empresas, conforme o impacto ambiental de suas atividades (art. 170, incisoVI).

Por oportuno, o constituinte de 1988 não se limitou a plasmar o princípio da sustentabilidade ambiental apenas nos capítulos da Ordem Econômica e do Meio Ambiente, mas tratou de promovê-lo em outros dispositivos constitucionais, como o fez ao disciplinar a destinação da Contribuição de intervenção no domínio econômico relativa às atividades de importação ou comercialização de petróleo e seus derivados, gás natural e seus derivados e álcool combustível, o constituinte derivado determina que parcela do produto arrecadado com esta exação seja para fomentar projetos ambientais relacionados com a indústria do petróleo e do gás, nos termos do art. 177, $\$ 4^{\circ}$, inciso II, alínea b. Ainda, vale realçar a norma inserta no art. 192, caput, da CF/88, que dispóe sobre o Sistema Financeiro Nacional, e indica que sua estruturação precisa contribuir para o desenvolvimento equilibrado do país, garantindo, desse modo, os interesses coletivos e, bem assim, no art. 219 (capítulo da Ciência, Tecnologia e Inovação), o constituinte prescreve que o mercado interno deve ser incentivado de maneira "a viabilizar o desenvolvimento cultural e sócio-econômico, o bem-estar da população e a autonomia tecnológica do País". Dos mencionados dispositivos é possível extrair a exegese de que, de fato, toda e qualquer ação antrópica ou atividade econômica deve considerar como premissa básica o bem-estar das pessoas e dos demais seres vivos que compõem o habitat natural, sem olvidar de, na mesma proporção, respeitar o meio ambiente cultural e o meio ambiente do trabalho.

No âmbito infraconstitucional, apenas à guisa de exemplo, merecem destaque: 1) a Lei no 8.666/93 que traz normas gerais federais sobre licitações e contratos - prescreve, em seu art. $3^{\circ}$, que o processo licitatório deve observar, dentre outros princípios, o "desenvolvimento nacional sustentável"; 2) a Lei no 12.187/2009, que instituiu a Política Nacional sobre Mudança do Clima - PNMC, estabelece a adoção de medidas que estimulem o desenvolvimento de processos e tecnologias, com vistas a contribuir para a economia de baixo carbono, criando critérios de preferência àquelas propostas, em licitações públicas, que demonstrem maior economia dos recursos naturais; e 3) a Resolução no 4.327, editada pelo Conselho Monetário Nacional em 25 de abril de 2014, estabelecendo diretrizes e implementando a Política de Responsabilidade Socioambiental das instituições financeiras e demais instituições autorizadas a funcionar pelo Banco Central do Brasil. Tal normativa é um marco importante, pois impõe ao setor financeiro uma obrigação de observar critérios de riscos ambientais em suas 
transações, nos termos do art. $8^{\circ}$, in verbis: "As instituições mencionadas no art. $1^{\circ}$ devem estabelecer critérios e mecanismos específicos de avaliação de risco quando da realização de operações relacionadas a atividades econômicas com maior potencial de causar danossocioambientais".

Nessa senda, é indubitavelmente cristalina a preocupação, pelo menos sob a perspectiva formal, do Estado brasileiro com a correlação entre tutela ambiental e atividades econômicas, especialmente na atualidade em que mudanças do clima, aumento de poluentes na atmosfera e nas águas têm colocado em risco a saúde das pessoas e do próprio planeta, além de prejudicar o desenvolvimento econômico. A água, por exemplo, é insumo necessário em toda e qualquer etapa de produção de um bem ou serviço. Autoridades políticas, ambientalistas e universidades já estão tratando dos detalhes para a Conferência das Partes das Nações Unidas para Mudanças Climáticas (COP 21), que ocorrerá em dezembro de 2015 em Paris, onde os 196 Estados tentarão encontrar caminhos comuns para tentar amenizar as causas responsáveis por drásticas mudanças climáticas. Maureen Santos (vide http://www.cartacapital.com.br/) apresenta 21 pontos que poderão ser objeto de discussão no evento em comento. Destacam-se quatro tópicos, os quais, a nosso ver, merecem ser debatidos com profundidade:

13. REDD+: A discussão principal é se entra ou não mecanismos de mercado para o financiamento da Redução de Emissões por Desmatamento e Degradação (REDD+). O Brasil vem sendo categórico em suas afirmações contrárias ao mercado em REDD+, tendo apoio de organizações e movimentos sociais como os reunidos no Grupo Carta de Belém, que vem rebatendo a abordagem REDD+ por entender, entre outras críticas, que incluir mercado de carbono no financiamento dos projetos é incluir a compensação de emissões.

14. Bioenergia e CCS: é o garoto-propaganda da nova abordagem de no net loss. Denominado BECCS nas negociações, envolve o plantio de uma enorme quantidade de grama e monocultivo de árvores para queima de biomassa com fins de geração de eletricidade, capturando o $\mathrm{CO} 2$ emitido e bombeando para reservatórios geológicos subterrâneos.

15. Uso da terra: tema forte na negociação na qual vem se fortalecendo a abordagem em 'escala de paisagem' (landscape approach), que seria a integração entre florestas e produção agropecuária. $\mathrm{O}$ uso da terra entra intensamente na agenda de mitigação, mas também em adaptação. Ainda sobre este tema, existem os chamados co-benefícios, que estão relacionados a questões sociais e também a proteção da biodiversidade.

16. Agricultura climaticamente inteligente (CSA): agricultura que aumenta a produtividade com resiliência (adaptação), ao mesmo tempo em que sequestra gases de GEE sem efetivamente reduzi-los, já que os créditos de redução seriam vendidos para outros locais poderem continuar emitindo. As formas de 
financiamento seriam por meio da medição e mercantilização do carbono do solo. Existe pressão para que a CSA entre no novo acordo, especialmente por parte da Organização das Nações Unidas para Alimentação e Agricultura (FAO) e do Banco Mundial.

Apesar das complexidades que perpassam pelas questões ambientais, o diálogo deve ser permanente, pois este parece ser o caminho mais racional para se encontrar soluções, ainda que não sejam ótimas, mas que contribuam para mudanças de paradigmas globais por parte de todos os atores sociais (Estados, indivíduos e empresas).

Além da função do Poder Público de planejar ações voltadas à proteção e à preservação dos recursos naturais, cumpre ressaltar o papel dos indivíduos e das empresas. É necessário que as pessoas revejam suas condutas com vistas a contribuir para a gestão sustentável das riquezas naturais, em especial, daságuas.

A rigor, em um contexto no qual a demanda por bens e serviços cresce vertiginosamente, a conjugação de planejamento e gestão séria e responsável é fundamental para garantir a sustentabilidade das águas e demais recursos naturais. Isso especialmente quando se verifica que, no mundo contemporâneo, em paralelo ao crescimento da economia, da ciência e da tecnologia, ampliam-se os causadores de poluição e seus nefastos efeitos.

Algumas empresas, embora ainda haja longo caminho a percorrer para atingir o equilíbrio entre desenvolvimento econômico e sustentabilidade ambiental, têm demonstrado preocupação e interesse em transformar as velhas práticas produtivas. Algumas indústrias, por exemplo, vêm introduzindo instrumentos tecnológicos, para que seus produtos causem menos impactos ambientais. Ou seja, os gestores começam a se conscientizar de que a sustentabilidade ambiental não é apenas um mero conceito acadêmico, mas que deve ser parâmetro no âmbito do universo empresarial. Nesse sentido, merecem destaque alguns exemplos:

1. A Golden Tecnologia, empresa voltada à produção têxtil, desenvolveu a tecnologia Dye Clean, para redução de até $80 \%$ do uso da água no tingimento detecidos;

2. A empresa Alstom desenvolveu "um sistema desulforizador a base de água do mar", utilizado para o "controle ambiental de plantas de papel e celulose, siderurgia e energia que emitem gases ricos em particulados como o enxofre, que é um dos responsáveis pela ocorrência de chuvas ácidas", esclarece Carmen Lúcia Nery (Revista Valor Especial.Junho, 2012)

3. A empresa REWATT desenvolveu a tecnologia simples do chuveiro racional. Segundo o detentor da patente do referido chuveiro, Geraldo Magalhães, com esta inovação - testada e aprovada pela CEMIG Centrais Elétricas de Minas Gerais - é possível obter até 50\% de economia no consumo de energia elétrica (TORIKACHVILI'in: Jornal O VALOR.Jan.2012). 
No Brasil, como em outras partes do mundo, ampliaram-se significativamente os processos de reuso (reaproveitamento) das águas, bem como o aproveitamento daquelas oriundas das chuvas. Conforme Regina Helena P. Costa (COSTA, 2007), o reuso compreende o "aproveitamento do efluente após uma extensão de seu tratamento, com ou sem investimentos adicionais". As indústrias, principalmente aquelas para as quais a água não é apenas um líquido vital, mas serve também como matéria prima para a fabricação de seus produtos, a exemplo das indústrias de refrigerantes e de cervejas, têm se preocupado em adotar técnicas de reuso de água, em especial para atividades de resfriamento de máquinas e de limpeza de equipamentos, ou para descarga de banheiro e limpeza geral.

É fato que no âmbito das relações negociais, por muito tempo, a visão empresarial conferia prioridade à tese de que o lucro era o objetivo maior das suas atividades - aspecto objetivo - e os acionistas eram considerados os principais atores de uma sociedade - aspecto subjetivo. Hodiernamente, o lucro e os investidores (acionistas) continuam ocupando espaço de destaque; porém, outros elementos, como o empregado, a comunidade local e o Meio Ambiente (o qual enfeixa o Meio Ambiente do Trabalho; o Artificial, construído pelo homem; o Cultural e o Natural, que compreende todos os microssistemas ecológicos) passaram a interagir com esta realidade. Nesse sentido dispõe o art. 116, parágrafo único, da Lei 6.404/76 (diploma normativo das sociedades por ações):

Parágrafo único. O acionista controlador deve usar o poder com o fim de fazer a companhia realizar o seu objeto e cumprir sua função social, e tem deveres e responsabilidades para com os demais acionistas da empresa, os que nela trabalham e para com a comunidade [insere-se aqui o direito ao meio ambiente saudável e equilibrado] em que atua, cujos direitos e interesses deve lealmente respeitar e atender (sem grifos no original).

Ou seja: a função social da empresa funda-se em quatro interesses/direitos distintos, os dos acionistas, dos empregados, da comunidade local e do meio ambiente. Nesse diapasão, preceitua José Edvaldo Tavares Borba (BORBA, 2012):

A sociedade anônima deixa de ser um mero instrumento de produção de lucros para os detentores do capital (acionistas), para elevar-se à condição de instituição destinada a exercer o seu objeto para atender aos interesses de acionistas, empregados e comunidade.

Nesse contexto, importante ressaltar os 17 Objetivos do Desenvolvimento Sustentável (ODS), lançados pela Organização das Nações Unidas (ONU), em agosto de 2015, e as 169 metas correspondentes, fruto do consenso obtido pelos delegados dos Estados-membros da ONU, para 2030 (vide http:/ /www.itamaraty.gov.br). A nova Agenda de Desenvolvimento, oficialmente adotada pelos Chefes de Estado e de Governo do mundo todo, na "Cúpula das Nações Unidas para o Desenvolvimento Sustentável 2015”, que teve lugar na sede da ONU, em Nova York, de 25 a 27 de setembro de 2015, contempla aspectos econômicos e ambientais, além dos sociais, os quais passam a valer para países pobres e ricos. Dessa forma, cria-se uma agenda objetiva para os próximos 15 anos, ampliando para o campo ambiental e econômico, o que antes tinha foco no âmbito social, consoante a Declaração do Milénio das Nações Unidas, aprovada na Cimeira do Milénio realizada de 6 a 8 de Setembro de 2000, em Nova Iorque. 
Se do lado da demanda o enfoque é do consumo sustentável (GOLEMAN, 2012), sob o prisma da oferta a tendência e a preocupação passam a ser em relação à forma e ao impacto da incorporação dos "novos" custos ambientais aos preços de produtos e serviços. Os efeitos desses custos ambientais sobre o mercado de bens e serviços dependem de múltiplas variáveis, inclusive do arcabouço normativo tributário, matéria a ser examinada no próximo capítulo, e bem assim do modelo produtivo em que se insere o segmento do negócio empresarial. É nesse contexto que tanto as inovações como as novas tecnologias passam a ocupar papel central no âmbito das instituições públicas e privadas, em especial nas áreas de energias renováveis, saneamento básico, florestas e agricultura de baixo carbono. Com efeito, a inovação está presente em 10 dos 17 ODS, sendo explícita na ODS de no 9: "Build resilient infrastructure, promote inclusive and sustainable industrialization and foster innovation", ou seja, "construir uma infraestrutura resiliente, promover uma industrialização sustentável e inclusiva, além de fomentar a inovação”.

Assim, na atualidade, a função socioambiental da empresa importa responsabilidade ambiental e uma reflexão sobre uma nova ética social, na qual o Meio Ambiente assume relevo no tocante à concretização de uma vida saudável e digna. A interconexão entre ética, educação, dever de cuidado, responsabilidade e tecnologia é necessária na disciplina das relações entre o homem e o Meio Ambiente, quaisquer que sejam essas relações (de lazer, de trabalho, de consumo, entre outras). Os governantes, os empreendedores e os consumidores precisam, efetivamente, prestar atenção a esses aspectos para que possam (re) construir verdadeiramente um mundo sustentável, saindo do mero discurso para a prática.

\section{A TRIBUTAÇÃO E O MERCADO EM FACE DA SUS TENTABILIDADE AMBIENTAL}

São múltiplas as conexões entre o mercado (onde ocorre a produção e o consumo de bens e serviços, e são estabelecidos os respectivos preços), a tributação e o meio ambiente natural, matéria que se projeta sobre a gestão da atividade econômica privada e bem assim sobre as finançaspúblicas.

O ordenamento normativo conforma a denominada incidência jurídica-tributária, a partir de eventos do mundo real que denotem signos de riqueza, sendo que as consequências econômicas da exigência dos tributos dependem de diversas variáveis, inclusive da interpretação/aplicação da norma impositiva.

O tipo de bem e serviço objeto de incidência, a estrutura de mercado e da remuneração dos fatores de produção, em que se insere o objeto da tributação, a espécie de tributo adotado, bem como o substrato econômico de incidência escolhido determinam os efeitos econômicos da incidência, os quais podem ser examinados sob o enfoque da microeconomia ou da macroeconomia. Saliente-se, ainda, os inúmeros efeitos em potencial que a tributação pode causar sobre a concorrência entre os diversos agentes do mercado, na hipótese de regras tributárias não isonômicas. 
A pessoa eleita pela norma jurídica como sujeito passivo da obrigação tributária (art. 121 do Código Tributário Nacional - CTN) e aquela que arca com o encargo financeiro do tributo (art. 166 do CTN) podem coincidir ou não. Ou seja, o chamado contribuinte de direito pode ser ou não a mesma pessoa que o denominado contribuinte de fato, tendo em vista que a imposição de tributos pode ocasionar alterações na remuneração dos fatores de produção ou nos preços dos bens e serviços. Com efeito, o repasse do encargo financeiro do tributo ao contribuinte de fato pode ser total ou parcial, dependendo das condições demercado.

Dito de outra maneira: as alterações de preços fixados nos mercados de bens e serviços e de fatores de produção podem redirecionar o ônus econômico e financeiro do tributo para pessoa diversa daquela indicada pela lei como o contribuinte de direito. Considerando o exposto, ensina Harvey Rosen (ROSEN, 1995):

The statutory incidence of a tax indicates who is legally responsible for the tax. (...) But the situations differ drastically with respect to who really bears the burden. Because prices may change in response to tax, knowledge of statutory incidence tells us essentially nothing about who is really paying the tax. (...) In contrast, the economic incidence of a tax is the change in the distribution of private real income brought by a tax. Complicated taxes may actually be simpler for a politician because no one is sure who actually ends up paying them. (grifo nosso)

Em sentido análogo apontam Marco Antonio Vasconcellos e Manuel Garcia (VASCONCELLOS et al, 2006):

A proporção do imposto pago por produtores e consumidores é a chamada incidência tributária, que mostra sobre quem recai efetivamente o ônus do imposto. Há uma diferença entre o conceito jurídico e o conceito econômico de incidência. Do ponto de vista legal, a incidência refere-se a quem recolhe o imposto aos cofres públicos; do ponto de vista econômico, diz respeito a quem arca efetivamente com o ônus. (grifo nosso)

Com efeito, independentemente da denominação jurídica conferida, ou, da distribuição constitucional de competências tributárias entre os diversos entes políticos em uma Federação, são três os substratos de incidência tributária sob o ponto de vista econômico: o patrimônio, a renda e o consumo.

Sob o ponto de vista jus-filosófico o poder de instituir e cobrar tributos, principal fonte de financiamento dos gastos públicos, pode ser justificado em razão da soberania do Estado (BASTOS, 1997) ou fundamentado na abertura permitida pelos direitos humanos fundamentais (TORRES, 1999), diretriz que depende da doutrina adotada.

Por outro lado, sob a perspectiva empresarial, os tributos são custos ou despesas, que podem reduzir a margem de lucro e a taxa de retorno do empresário ou, ainda, serem incorporados aos preços de bens e serviços e repassados aos consumidores finais. Como já destacado, nem sempre a pessoa eleita pela norma jurídica como o sujeito passivo da obrigação tributária - o contribuinte de direito-, é aquele que arca, na realidade, com o ônus econômico do tributo, enquadramento que depende das forças que atuam no mercado de fatores de produção e do mercado de bens e serviços. 
Em outras palavras: independentemente do substrato econômico de tributação utilizado (patrimônio, renda ou consumo), o contribuinte de fato, assim qualificado por suportar o encargo financeiro da incidência, pode ser ou não a mesma pessoa que o contribuinte de direito, que tem o dever jurídico de pagar o tributo, por determinação legal (o sujeito passivo da obrigação tributária).

Vale repisar que essa possível dissociação decorre dos múltiplos efeitos dos tributos sobre os preços e condições dos mercados de bens e serviços e dos fatores de produção (terra, capital, trabalho, tecnologia etc.), do tipo de exação assim como da própria aplicação da norma jurídica de incidência, conforme acima salientado. Nesse sentido ensinam Marco Antonio Vasconcellos e Manuel Garcia (Op. Cit.):

O produtor procurará repassar a totalidade do imposto ao consumidor. Entretanto, a margem de manobra de repassá-lo dependerá do grau de sensibilidade desse a alterações do preço do bem. E essa sensibilidade (ou elasticidade) dependerá do tipo de mercado. Quanto mais competitivo ou concorrencial o mercado, maior a parcela do imposto paga pelos produtores, pois eles não poderão aumentar o preço do produto para nele embutir o tributo. O mesmo ocorrerá se os consumidores dispuserem de vários substitutos para esse bem. Por outro lado, quanto mais concentrado o mercado - ou seja, com poucas empresas -, maior grau de transferência do imposto para consumidores finais, que contribuirão com parcela do imposto.

Em suma, essa interação, entre a incidência do tributo e os preços dos bens e serviços, estabelece a correlação fundamental para determinação de quem suporta o ônus do tributo: o contribuinte de direito, o contribuinte de fato ou se ocorrerá uma repartição do encargo entre os agentes econômicos e o consumidor final. Seja qual for esse impacto econômico do tributo, na cadeia de produção, circulação e consumo, fato é que a sua incidência afeta o custo, e o preço, de bens e serviços. Mas qual a relevância dessa intrincada correlação entre a tributação e o mercado sobre o meio ambiente? A resposta é simples: dependendo da política tributária adotada, pode ser estimulado ou desestimulado o consumo e, por conseguinte a produção, de determinados produtos e serviços, os quais podem impactar o meio ambiente natural de forma mais branda ou de maneira mais aguda, dependendo do modo de produção e insumos utilizados.

Consideradas essas premissa, importante ressaltar que na relação entre a tributação e a preservação do meio-ambiente há alternativas voltadas para a adoção (i) de um sistema desestimulador/punitivo de ações e comportamentos ou (ii) de um sistema de incentivos.

Com efeito, os princípios da sustentabilidade ambiental na produção econômica de bens e serviços e do meio ambiente ecologicamente equilibrado projetam-se sobre três dimensões distintas da tributação: (i) o viés impositivo das normas disciplinadoras dos tributos já existentes no atual Sistema Tributário Nacional, especificamente no que concerne à determinação da base de cálculo do tributo e/ou a fixação de alíquotas mais elevadas; (ii) a vertente da concessão de benefícios e incentivos fiscais relativamente aos tributos citados no item (i); e (iii) os tributos ambientais em sentido estrito, a serem possivelmente instituídos e cujos aspectos materiais de incidência contenham elemento(s) ou parâmetro(s)ambiental(is). 
Ao optar pela adoção de um sistema desestimulador/punitivo, prioriza-se a função fiscal arrecadatória do tributo. Embora o tributo não corresponda juridicamente a uma sanção contra ato ilícito, a incidência mais gravosa pode onerar financeiramente de forma mais acentuada o poluidor, aumentando o custo de poluir e combater as denominadas "externalidades negativas". Trata-se do modelo pigouviano de internalização do custo social decorrente de danos provocados ao meio-ambiente (PIGOU, 1967). Nesse caso, o Estado arrecada e pode direcionar os recursos à preservação ambiental, a depender da espécie tributária em questão.

Como já destacado, além dessa estratégia, o Poder Público pode optar por criar incentivos para que os agentes atuem preventivamente. Dentre os mecanismos para criar tais incentivos, é possível optar por desonerar o contribuinte. Desse modo, por meio da concessão de benefícios e incentivos fiscais, o Poder Público incentiva o comportamento dos agentes privados sem incorrer nos custos atrelados à instituição de um tributo. Na prática, porém, a matéria envolve discussões sobre os limites e parâmetros a serem adotados pelo legislador que cria e estabelece a dispensa do tributo.

Nessa linha de intelecção, deve-se reconhecer que a sustentabilidade ambiental na produção econômica de bens e serviços, apesar de não constar expressamente da Constituição Tributária e Orçamentária (artigos 145 a 169), consubstancia parâmetro atual e requisito futuro necessário à concessão de benefícios fiscais, de acordo com uma interpretação sistemática e teleológica da Constituição da República Federativa do Brasil de 1988, a despeito de os formuladores da política tributária nacional não observarem esse vetor axiológico implícito primário, verdadeiro imperativo constitucional sistêmico. Na realidade, tem sido comum no Brasil e em diversos países do mundo a concessão de incentivos fiscais para a indústria automotiva e petrolifera, cujas atividades e cadeia produtiva são reconhecidas como uma das principais causadoras da emissão de dióxido de carbono na atmosfera, os quais tem sido apontados como os vilões para o aquecimento global. Nesse sentido apontam Reuven S. AviYonah e David M. Uhlmann (videhttp://ssrn.com/abstract=1333673):

Both carbon tax and cap and trade system could be imposed either 'upstream' or 'downstream'. As Part III discusses in great detail below, an upstream carbon tax or cap and trade system would focus on fossil fuel production (oil, coal, and natural gas), since together energy accounts for approximately eighty percent of carbon dioxide emissions in the United States. An up-stream market-based approach would have the greatest ability to ensure that all sources of carbon dioxide emissions are affected because it focuses on carbon at the point that it enters the economy. Alternatively, either a carbon tax or a cap and trade system could be imposed downstream on the facilities that are the major sources of carbon dioxide emissions. (...) A well-designed downstream approach could also reach all sectors of the economy, enabling costs to be distributes as evenly as an upstream approach. The challenge under a downstream approach is the number and kinds of facilities that would be monitored and the inherent difficulty in reaching all forms of energy use, most notably motor vehicle use and electricity, which contribute significantly to carbon dioxide emissions.

É nesse contexto que se estabelece a intrincada e inquestionável correlação entre o mercado (onde ocorre a produção e o consumo de bens e serviços, e são estabelecidos os respectivos preços), a tributação e o meio ambiente natural, matéria que se projeta sobre a gestão da atividade econômica privada e bem assim sobreas vol.09, nº. 02, Rio de Janeiro, 2016. pp. 843-860 
finanças públicas. Com efeito, a complexidade do tema decorre, de um lado, da citada correlação entre os preços que se formam no mercado e o impacto da tributação sobre os custos empresariais, e, de outro, dos efeitos sobre o meio ambiente das ações e comportamentos individuais e coletivos, privados e públicos, os quais são diretamente influenciados, incentivados ou desestimulados, pelas políticas tributáriasadotadas.

\section{CONSIDERAÇÕES FINAIS}

No cenário aqui apresentado fica evidente a necessidade de mudanças de paradigmas em relação ao meio ambiente natural, não apenas pela necessidade de se preservar e proteger os recursos naturais - os quais, em razão da demanda e dos variados agentes poluidores, estão em exaustão -, mas também para garantir as diversas modalidades de atividade econômica, que movimentam a economia, geram empregos e oportunidades, visto que a vida em relação impõe meios de sobrevivência.

Assim, adotar a Sustentabilidade Ambiental como vetor axiológico implícito primário, ou seja, como verdadeiro imperativo constitucional sistêmico, é condição necessária para a construção de uma economia de mercado que visa a harmonizar o equilíbrio dos ecossistemas com as atividadeseconômicas.

Nesse sentido, devem ser criadas as condições para que os empreendedores públicos ou privados, ao desenvolverem produtos, considerem como custos adicionais aqueles de natureza ambiental.

Por fim, reconhece-se a importância do Tributo, como instrumento idôneo para acelerar o processo de novas práticas empresariais, nas quais a sustentabilidade deve ser premissa básica em toda a cadeia de produção: da elaboração do produto até seu descarte.

\section{ENVIRONMENTAL SUSTAINABILITY: REQUIRED PARAMETER TO THE ECONOMIC ACTIVITY AND ESSENTIAL REQUIREMENT THE GRANTING OF TAX BENEFITS}

\section{Summary}

This text aims to demonstrate the importance of correlation between the principle of environmental sustainability, economic activity and the granting of tax benefits, as a way to go for the balance of the natural environment and as an instrument of environmental education, whereas imperative need for change of paradigms, in which the ethics of care must be elevated to the level of fundamental premise because nature can no longer be treated as a mere object available to the man. In fact, part of the joint analysis of multiple nuances of sustainability.

Keywords: environmental sustainability; economic activity; taxing; law. 


\section{REFERENCIAS}

AHMED, Flavio. Meio ambiente cultural e educação ambiental: uma pedagogia da cidadania. In: CARLI, Ana Alice De; MARTINS, Saadia B. (organizadoras). Educação Ambiental: premissa inafastável ao desenvolvimento econômico sustentável. Rio de Janeiro: Editora Lumen Juris, 2014.

AINSWORTH, Richard Thompson. Phishing \& VAT fraud in Co2 permits: dice in the eu-ets now; dice in power tomorrow. In: CARLI, Ana Alice De; COSTA, Leonardo de Andrade e RIBEIRO, Ricardo Lodi (orgs). Tributação e Sustentabilidade Ambiental. Rio de Janeiro: Ed. FGC,2015.

AVI-YONAH, Reuven S. and UHLMANN David M. Why a carbon tax is the best way to address global climate change. In: CARLI, Ana Alice De; COSTA, Leonardo de Andrade e RIBEIRO, Ricardo Lodi (orgs). Tributação e Sustentabilidade Ambiental. Rio de Janeiro: Ed. FGC, 2015.

BARLOW, Maude e CLARKE, Tony. Ouro Azul: como as grandes corporações estão se apoderando da água doce do nosso planeta. Tradução de Andreia Nastri. Tradução de atualizações de Natália Coutinho Mira de Assumpção. São Paulo: Editora M. Books do Brasil,2003.

BASTOS, Celso Ribeiro. Curso de Direito Financeiro e de Direito Tributário. 5. ed. atual. São Paulo: Editora Saraiva, 1997.

BORBA, José Edwaldo Tavares. Direito Societário. Rio de Janeiro: Ed. Renovar,2012.

BRASIL. Poder Judiciário. Supremo Tribunal Federal. ADI 3540-MC, Pleno. Rel. Min.Celso de Mello. Julgamento em 1.09.2005. Brasília. Disponível em: < http://www.stf. jus.br >. Acesso em 09.04.2012.

CARLI, Ana Alice De. A Água e seus instrumentos de efetividade: educação ambiental, normatização, tecnologia e tributação. São Paulo: editora Millennium,2013.

A Contribuição Especial da Água: novo tributo de arrecadação zero na hipótese de consumidor ecologicamente consciente. In: CARLI, Ana Alice De; COSTA, Leonardo de Andrade e RIBEIRO, Ricardo Lodi (organizadores). Tributação e Sustentabilidade Ambiental. Rio de Janeiro: Ed. FGV, 2015, pp. 11-26.

Água é vida: eu cuido, eu poupo - para um futuro sem crise. Coleção FGV de Bolso. Série Direito e Sociedade, nº 39. Rio de Janeiro: Editora FGV,2015.a.

CECHIN, Andrei. A natureza como limite da economia: a contribuição de Nicholas Georgescu-Roegen. São Paulo: Editora Senac/Edusp, 2010.

CHIARETTI, Daniela entrevista Achim Steiner. Jornal O Valor, publicação de 19,20 e 21 de setembro de 2015, seção A1 1, São Paulo.

CIRRA- Centro Internacional de Referência em Reuso de Água. Tipos de Reuso. Universidade de São Paulo USP. Disponível em <http://www.usp.br/cirra/>. Pesquisa realizada em21.08.2012.

COASE. Ronald. The Problem of Social Costs (1960). Disponível em: http://www.econ.ucsb.edu/ tedb/Courses/UCSBpf/readings/coase.pdf. Acesso em02.09.2015.

COELHO, Saulo de Oliveira P. e ARAUJO, André Fabiano G. A Sustentabilidade como Princípio Constitucional Sistêmico e sua relevância na efetivação interdisciplinar da Ordem Constitucional Econômica e Social: para além 
do ambientalismo e do desenvolvimentismo. Disponível em https://mestrado.direito.ufg.br/up/14/o/artigo_prof_saulo.pdf. Acesso em 13.09.2015.

COOK, Karen Schwers e LEVI Margaret. The limits of rationality. Chicago.

COSTA, Leonardo de Andrade et al. Os trade-offs na imposição de restrições ou perda de incentivos e benefícios fiscais com fundamento na política nacional do meio ambiente. In: CARLI, Ana Alice De; COSTA, Leonardo de Andrade e RIBEIRO, Ricardo Lodi (organizadores). Tributação e Sustentabilidade Ambiental. Rio de Janeiro: Ed. FGV, 2015, pp. 27-44.

A sustentabilidade ambiental na produção econômica de bens e serviços como requisito progressivo à concessão de incentivos e benefícios fiscais no Brasil. In: FLORES, Nilton Cesar (organizador). A Sustentabilidade Ambiental em suas Múltiplas Faces. São Paulo: Editora Millennium, 2012, pp. 161-196.

MAGALHÃES, José Veiga e COSTA, Leonardo de Andrade. Reeducação para adoção de uma metodologia sustentável de produtação como requisito progressivo à concessão de benefícios fiscais para a indústria. In: CARLI, Ana Alice e MARTINS, Saadia Borba (organizadoras). Educação Ambiental: premissa inafastável ao desenvolvimento econômico sustentável. Rio de Janeiro: Lumen Juris, 2014.p.289/302.

COSTA, Regina Helena Pacca. Reuso. In: In: TELLES, Dirceu D'Alkmim e COSTA, Regina Helena Pacca G. (organizadores). Reúso da Água: conceitos, teorias e práticas. São Paulo: Editora Blucher, 2007, pp. 153-207.

CUNHA, Viviane. O que é a Certificação Breeam? Disponível em <http://www.vivianecunha.com.br/>. Pesquisa realizada em 14.08.2012.

DECISION Report. Sabesp usa telemetria para medição de água. Disponível em $<$ www.projetoecoinovacao.com.br/>. Pesquisa realizada em 14.08.2012.

FEBRABAN. Bancos financiam Economia Verde. Disponível em http://www.febraban.org.br. Acesso em 24.09.2015.

GEORGESCU ROEGEN, Nicholas. O decrescimento: entropia, ecologia, economia. Apresentação e Organização Jaques Grinevald e Ivo Rens. Tradução Maria José Perillo Isaac. São Paulo: Editora Secac, 2012.

GETTING THE DEAL THROUGH. Climate Regulation in 17 jurisdictions worldwide. 2014. p. 35. Disponível em: https://gettingthedealthrough.com/books/42/climate-regulation/.Acesso em02.09.2015.

GRAU, Eros Roberto. A Ordem Econômica na Constituição de 1988. 8 ed. São Paulo: Editora Malheiros,2003.

HARDING, Stephan. Terra Viva: ciência, intuição e a evolução de gaia. Tradução de Mario Molina. São Paulo: Editora Cultrix, 2008.

KNOBLOCK, M. D., SUTTON, P. M., MISHRA, P. N., GUPTA, K. \& JANSON, A. Membrane Biological Reactor System for Treatment of Oily Wastewaters. Disponível em <http://www.jstor.org/>. Pesquisa realizada em 17.08.2012.

MACHADO, Hugo de Brito. Curso de Direito Tributário. 21 ed. rev. atual. e ampl. São Paulo: Editora Malheiros, 2002. 
MODÉ, Fernando Magalhães. Tributação Ambiental: a função do tributo na proteção do meio ambiente. Curitiba: Ed. Juruá, 2006.

MOITAS, Danielle. Cedae anuncia projeto de reuso de água para o Comperj. Disponível em $<$ http://portomaravilha.com.br/>. Pesquisa realizada em 15.08.2012.

NERY, Carmen Lúcia. Grandes Ideias que também ajudam a cuidar do planeta: são cada vez mais frequente iniciativas inovadoras com impacto positivo sobre o meio ambiente e comunidades. Revista Valor Especial.Junho, 2012, São Paulo: Editora Valor Econômico, pp. 132-133.

NUSDEO, Fábio. Sustentabilidade. In: MARQUES, José Roberto (organizador). Sustentabilidade e Temas Fundamentais de Direito Ambiental. Campinas, SP: Editora Millenium, 2009.

PETERS, Madelon Rebelo. Potencialidade de Uso de Fontes Alternativas de Água para fins não Potáveis em uma Unidade Residencial. Tese de Mestrado em Engenharia Ambiental na Universidade Federal de Santa Catarina. Disponível em <http://pt.scribd.com/>. Pesquisa realizada em 18.08.2012.

PIGOU, Arthur Cecil. The Economics of Welfare. 4a ed. London: Macmillan \& Co., 1962.

ROSEN, Harvey S. Public Finance - 4th ed. United States: Irwin, 1995. Chapter 13, p. 273 a302.

SANTOS, Maureen. Entenda a COP 21 e as disputas em jogo. Disponível em http://www.cartacapital.com.br/. Acesso em 24.09.2015.

SLAPER, Timothy F e HALL ,Tanya J. The Triple Bottom Line: What Is It and How Does It Work? Disponível em <http://www.ibrc.indiana.edu/ibr/2011/spring/article>. Acesso em22.09.2015.

TORRES, Ricardo Lobo. Tratado de Direito Constitucional Financeiro e Tributário. Vol. III. Os Direitos Humanos e a Tributação - imunidades e isonomia. Rio de Janeiro: Editora Renovar, 1999.

VASCONCELLOS, Marco A.S. e GARCIA, Manuel E. Fundamentos de Economia. 2 ed. São Paulo: Editora Saraiva, 2006.

Trabalhoenviadoem25denovembrode2015.

Aceitoem 12 dejaneiro de 2016. 